\title{
Lifestyle risk indices in adolescence and their relationships to adolescent disease burden: findings from an Australian national survey
}

\author{
Louise Mewton ${ }^{*}$ (D), Katrina Champion, Frances Kay-Lambkin, Matthew Sunderland, Louise Thornton and \\ Maree Teesson
}

\begin{abstract}
Background: The current study investigates the extent to which an adolescent-specific lifestyle risk factor index predicts indicators of the leading causes of adolescent morbidity and mortality.

Methods: Data came from 13 to 17 year-old respondents from the 2013-2014 nationally representative Australian Child and Adolescent Survey of Mental Health and Wellbeing $(n=2314)$. Indicators of adolescent disease burden included Major Depressive Disorder, psychological distress, self-harm and suicide attempt. Risk factors included risky alcohol use, drug use, unprotected sex, smoking, BMl and sleep duration. The extent to which these risk factors cooccurred were investigated using tetrachoric correlations. Several risk indices were then constructed based on these risk factors. Receiver Operating Characteristic curves determined the precision with which these indices predicted the leading causes of adolescent disease burden.
\end{abstract}

Results: Risky alcohol use, drug use, smoking, unprotected sex, and sleep were all highly clustered lifestyle risk factors, whereas BMI was not. A risk index comprising risky alcohol use, drug use, unprotected sex and sleep duration predicted the disease burden outcomes with the greatest precision. 31.9\% of the sample reported one or more of these behaviours.

Conclusions: This lifestyle risk factor index represents a useful summary metric in the context of adolescent health promotion and non-communicable disease prevention. Lifestyle risk factors were found to cluster in adolescence, supporting the implementation of multiple health behaviour change interventions.

Keywords: Adolescence, Lifestyle risk factors, Burden of disease

\section{Background}

Whilst adolescence and young adulthood is often thought of as a period of relative good health, burden of disease studies indicate that 10-24 year olds remain at substantial risk of morbidity and mortality [1]. Burden of disease in this age group is not driven by physical illness, but by mental illness, self-harm and suicide. Meanwhile, the leading risk factors contributing to this burden of disease in young people include risky alcohol use, illicit drug use and

\footnotetext{
* Correspondence: louisem@unsw.edu.au

Centre of Research Excellence in Mental Health and Substance Use, National Drug and Alcohol Research Centre, University of New South Wales, 22-32 King St, Randwick, NSW 2032, Australia
}

unprotected sex $[2,3]$. These risk factors are not only associated with poor outcomes for youth in the short-term, such as obesity and mental health problems, but are also associated with morbidity and mortality experienced later in life [4-7]. Evidence has consistently shown that these risk behaviours are linked to the development of later chronic non-communicable conditions, such as heart disease, cancer and Type II diabetes, which cause considerable disease burden amongst older adults [8-10]. Experts have therefore suggested that chronic health disease risk factor management should begin in adolescence, as evidence is accumulating on the benefits of early intervention for future health gains [11]. Identifying clusters of 
potentially modifiable risk behaviours associated with morbidity and mortality amongst adolescents, and risk for later chronic disease in adulthood, would ideally guide the development of preventive interventions designed to reduce the burden of disease across the lifespan.

Previous research has linked certain clusters of risk factors with indicators of mental health in young people. For example, the combination of concurrent risky alcohol use, drug use and smoking is related to increased depressive symptom severity in young people aged $15-30$ years [12], as has the clustering of physical inactivity, smoking, low-quality diet, and abnormal (high or low) body mass index (BMI) [4]. The cluster of smoking, alcohol misuse, marijuana use, sexual activity, violence, and suicidality has also predicted a range of psychopathology in children and adolescents aged 9-17 years, including mood, anxiety and disruptive disorders [13]. In another study, risky alcohol use, illicit drug use, smoking, sleep deprivation, overweight/underweight, sedentary behaviour, high media use, and truancy were related to a range of poor mental health outcomes, including depression, anxiety and suicidality amongst adolescents (mean age 14.9 years) [14]. Recent research has therefore recognised the importance of lifestyle risk factors in the determination of adolescent mental health. In the adult literature, the importance of these risk factors has led to the development of lifestyle risk indices comprised of factors related to disease burden in adults [7, 15]. To our knowledge, a similar index of adolescent-specific risk factors for burden of disease has not been constructed. It is envisaged that this lifestyle risk factor index could be used to easily identify adolescents at risk for chronic diseases of both adolescence and adulthood in a rigorous and standardised way. Those identified as at risk could then be targeted by healthy lifestyle interventions designed to reduce the burden of disease across the lifespan.

Using a large nationally representative sample of Australian adolescents, the current study will construct a lifestyle risk index comprising the leading risk factors for adolescent burden of disease (i.e., risky alcohol use, drug use and unprotected sex) [3]. The extent to which this index predicts indicators of the leading causes of adolescent morbidity and mortality (i.e., depression, psychological distress, self-harm and suicide attempt) will also be investigated. The study will also investigate whether the addition of conventional (i.e., smoking and $\mathrm{BMI}$ ) and emerging (i.e., sleep duration) risk factors associated with disease burden in adulthood $[7,14,16,17]$ improves the measurement properties of this index.

\section{Methods}

\section{Sample}

The 2013-2014s Australian Child and Adolescent Survey of Mental Health and Wellbeing was based on a stratified, multistage area probability sample of households where there was at least one child aged 4-17 years. The survey represents the most up-to-date, detailed snapshot of mental health and wellbeing in adolescents in Australia. In total 6310 parents and carers of eligible households participated in the survey, representing an overall response rate of 55\%. In addition, 2967 (89\%) of young people aged 11-17 years, for whom their parents or carers had given written consent, also gave written consent to complete a youth self-report questionnaire. Comparison with 2011 Australian Census data indicated that the sample was broadly representative of the Australian population in terms of demographic characteristics [18]. The survey data were weighted to represent the Australian population of children and adolescents aged 4-17 years based on 2013 data from the Australian Bureau of Statistics. The current study uses data from youth aged $13-17$ years $(n=2314)$. Those aged 11-12 did not provide data on the relevant risk behaviours and were therefore excluded from the current study. The survey received ethical approval from the Australian Government Department of Health. The survey methods have been discussed in more detail elsewhere [18] and full questionnaires used in the survey can be accessed here: https://youngmindsmatter.telethonkids.org.au/for-researchers/.

\section{Measures \\ Key variables accounting for morbidity/mortality in adolescence}

The 2013-2014s Australian Child and Adolescent Survey of Mental Health and Wellbeing included a self-report module based on the Diagnostic Interview Schedule for Children (DISC-IV) which was used to provide a 12-month diagnosis of major depressive disorder (MDD) [19]. The DISC-IV is designed for use in children and adolescents aged 6-17 years and has been shown to have acceptable test-retest reliability in community samples [19]. Questions from the Youth Risk Behavior Surveillance System (YRBSS) were also included in the survey and were used to provide data for the suicide attempt and self-harm outcomes [20]. Participants were asked whether they had attempted suicide in the past 12 months (suicide attempt) and whether they had deliberately harmed or injured themselves without intending to end their own life during the past 12 months (self-harm). Psychological distress in the past 4 weeks was measured by the 10-item Kessler Psychological Distress scale (K10) [21], which has been used previously in samples of adolescents in the Australian general population [22], and demonstrated excellent reliability in the current sample (Cronbach's $\alpha=0.91$ ). Those reporting severe psychological distress (scores 21 and above) were compared with those with scores below 
this standard cut-off [23]. The dichotomised version of the K10 has been used extensively, and has been shown to predict serious mental illness in both adolescents and adults with good accuracy [22, 24, 25].

\section{Risk factors}

Self-reported risky alcohol use, drug use, smoking, and unprotected sex were collected as part of the YRBSS. To evaluate an index based on these risk factors, each was coded as 0 (not at risk) or 1 (at risk). Alcohol risk was defined as consuming four or more standard drinks on a single occasion in the past 30 days, based on the Australian National Health and Medical Research Council's definition of single occasion risky drinking [26]. Respondents were asked to select which drugs they had used in the past 30 days from a list including cannabis, meth/ amphetamine, cocaine, ecstasy and prescription drugs for non-medical or non-prescribed purposes. Drug risk was defined as the use of any of these illicit drugs in the past 30 days. Those who had smoked cigarettes in the past 30 days were considered at smoking risk. Respondents were asked whether they used any form of protection to prevent pregnancy or sexually transmitted infections. Sexual risk was defined as those who reported using no form of protection the last time they had sexual intercourse. Youth were also asked to self-report their current height and weight [used to derive BMI (height $(\mathrm{m}) /$ weight $\left.^{2}(\mathrm{~kg})\right]$ and the average amount of sleep each week night and each weekend night (hours). Those with a BMI less than 18.5 or higher than 30 were considered at weight risk, according to standard guidelines of underweight and obesity from the Australian Government Department of Health [27]. Both ends of the BMI spectrum were considered given evidence suggesting that the relationship between mental health and BMI is U-shaped, with those who are both underweight and overweight at higher risk for mental health problems such as depression [28]. In addition, both weight gain and weight loss are considered symptoms of major depression [29]. Finally those who slept less than 7 hours and more than 11 hours per night on average were considered at sleep risk, according to Australian sleep guidelines for adolescents [30]. Sleep problems, which include both hypersomnia and insomnia, are associated with mental health problems, and are both considered symptoms of major depression [29].

We constructed a basic risk index, which consisted of risky alcohol use, drug use and unprotected sex, the leading risk factor associated with adolescent disease burden [2,3]. The basic risk index scores ranged from 0 to 3 . Three other specific risk indices were then created, comprising the basic index + smoking, the basic index + BMI and the basic index + sleep. Each of the specific risk index scores ranged from 0 to 4 . The basic index + smoking + BMI, the basic index + smoking + sleep, and the basic index $+\mathrm{BMI}+$ sleep were also constructed (scores ranging from 0 to 5). Finally, an index consisting of all six risk factors (risky alcohol use, drug use, unprotected sex, smoking, BMI and sleep) was constructed (ranging from 0 to 6 ).

Table 1 includes a description of each of the risk factors, as well as a summary of how each of the risk indices were composed.

\section{Statistical analyses}

All analyses were weighted to account for the complex survey design and were conducted using SAS 9.4. The prevalence of each risk factor and the four leading causes of disease burden in adolescence (self-reported MDD, suicide attempt, self-harm, severe psychological distress) were first analysed by key demographic variables: age, sex, rurality (classified as greater capital cities or rest of state, as per the Australian Bureau of Statistics' Australian Statistical Geography Standard), country of birth and current education status (whether or not the participant currently goes to school, as reported by the parent). The extent to which the risk factors co-occurred was also investigated using tetrachroic correlations. Preliminary analyses focused on whether the basic risk index (alcohol use, drug use and unprotected sex) predicted the four disease burden outcomes with greater precision than any single risk factor, or combination of two risk factors, that comprised this index. The predictive utility of the basic risk index was then compared with the seven other indices constructed as described above and in Table 1 . The predictive utility of these various combinations of risk factors was assessed using receiver operating characteristic (ROC) curves created with logistic regressions that controlled for demographic characteristics (age, sex, country of birth and education status) which were likely to be related to both the risk factors and indicators of burden of disease in young people.. The area under the curve (AUC) was calculated to describe how well each index classified the four causes of disease burden in adolescence, and to compare these indices in terms of predictive value. An AUC of 0.5 indicates that an index is no better than chance at predicting risk, whilst an AUC of 1.0 indicates that an index predicts risk perfectly. Areas under the curve for each index were compared with the basic risk index (reference index) using the ROCCONTRAST statement in SAS 9.4 which implements a nonparametric approach as recommended by methodological experts [31].

An optimal at-risk threshold (or cut-off) was then established for the index that predicted the four outcome variables with the highest precision. This optimal threshold was selected by comparing AUCs characterising the relationship between all possible thresholds on 
Table 1 Lifestyle factors, risk scoring methods and risk indices derived from the 2013-2014 Australian Child and Adolescent Survey of Mental Health and Wellbeing $(n=2314)$

\begin{tabular}{|c|c|c|c|c|c|c|c|c|c|}
\hline \multirow[b]{2}{*}{$\begin{array}{l}\text { Lifestyle } \\
\text { factor }\end{array}$} & \multirow[b]{2}{*}{$\begin{array}{l}\text { Risk Scoring } \\
\text { Method }\end{array}$} & \multicolumn{8}{|c|}{ Risk indices } \\
\hline & & Basic risk & $\begin{array}{l}\text { Basic risk } \\
+\mathrm{BMI}\end{array}$ & $\begin{array}{l}\text { Basic risk } \\
+ \text { Sleep }\end{array}$ & $\begin{array}{l}\text { Basic risk } \\
+ \text { Smoking }\end{array}$ & $\begin{array}{l}\text { Basic risk } \\
+ \text { BMI + Sleep }\end{array}$ & $\begin{array}{l}\text { Basic risk } \\
+\mathrm{BMI}+\text { Smoking }\end{array}$ & $\begin{array}{l}\text { Basic risk + Sleep } \\
+ \text { Smoking }\end{array}$ & $\begin{array}{l}\text { Basic risk + BMl } \\
+ \text { Sleep + Smoking }\end{array}$ \\
\hline Alcohol use & $\begin{array}{l}1=4 \text { or more } \\
\text { drinks on a } \\
\text { single occasion } \\
\text { in past month }\end{array}$ & $\checkmark$ & $\checkmark$ & $\checkmark$ & $\checkmark$ & $\checkmark$ & $\checkmark$ & $\checkmark$ & $\checkmark$ \\
\hline $\begin{array}{l}\text { Illicit drug } \\
\text { use }\end{array}$ & $\begin{array}{l}1=\text { past 30-day } \\
\text { illicit drug use }\end{array}$ & $\checkmark$ & $\checkmark$ & $\checkmark$ & $\checkmark$ & $\checkmark$ & $\checkmark$ & $\checkmark$ & $\checkmark$ \\
\hline $\begin{array}{l}\text { Unprotected } \\
\text { sex }\end{array}$ & $\begin{array}{l}1=n o \\
\text { protection used } \\
\text { against } \\
\text { pregnancy or } \\
\text { sexually } \\
\text { transmitted } \\
\text { diseases the last } \\
\text { time respondent } \\
\text { had sexual } \\
\text { intercourse }\end{array}$ & $\checkmark$ & $\checkmark$ & $\checkmark$ & $\checkmark$ & $\checkmark$ & $\checkmark$ & $\checkmark$ & $\checkmark$ \\
\hline $\mathrm{BMI}$ & $\begin{array}{l}1=\text { Body mass } \\
\text { index }<18.5 \text { or }> \\
30\end{array}$ & & $\checkmark$ & & & $\checkmark$ & $\checkmark$ & & $\checkmark$ \\
\hline Sleep & $\begin{array}{l}1=<7 h \text { or }>11 \\
h / \text { day }\end{array}$ & & & $\checkmark$ & & $\checkmark$ & & $\checkmark$ & $\checkmark$ \\
\hline Smoking & $\begin{array}{l}1 \text { = past 30-day } \\
\text { cigarette } \\
\text { smoking }\end{array}$ & & & & $\checkmark$ & & $\checkmark$ & $\checkmark$ & $\checkmark$ \\
\hline
\end{tabular}

the best performing index and the four disease burden outcome variables of interest. A threshold of one risk factor was first imposed on the best performing index, and AUCs were constructed describing the precision with which one risk factor predicted each of the disease burden outcome variables. A threshold of two risk factors was then imposed and AUCs were again constructed describing the precision with which a total of two risk factors predicted each of the disease burden outcomes variables. This procedure was then replicated for each possible threshold on the best performing risk index. Basic demographic characteristics of those identified as at-risk according to this optimal threshold were then described using univariate and multivariate logistic regression models.

\section{Results}

Overall, $48.7 \%$ of the sample were female, the mean age was $15.0,63.5 \%$ of the sample were from metropolitan areas, $85.8 \%$ were Australian born and $93.0 \%$ of the sample were currently attending school. Descriptive statistics by causes of disease burden outcomes and major risk behaviours are presented in Table 2. Based on tetrachoric correlations (Table 3), risky alcohol use, drug use, smoking, unprotected sex, and sleep were all significantly and highly clustered risk factors. BMI did not appear to cluster with these other factors.
Preliminary analyses focused on validating the basic risk index comprising alcohol use, drug use and unprotected sex. The basic risk index was found to predict the four disease burden outcomes with fair to good precision (Table 4), and with more accuracy than any of the composite risk factors either alone (i.e., alcohol use, drug use or unprotected sex) or in combination (i.e., alcohol use + drug use, alcohol use + unprotected sex or drug use + unprotected sex) (results available on request). Table 4 presents the AUCs for the basic risk index, as well as comparisons between this index and the AUCs for each of the calculated risk indices, in terms of their ability to predict the four disease burden outcomes. When comparing the different indices, the basic risk + sleep + smoking index predicted the disease burden outcomes with the greatest precision, and with greater precision than the basic risk index alone (all contrast $p$ s $<.01)$. The basic risk + sleep + smoking index was therefore selected as the most precise risk index predicting adolescent disease burden. Based on the basic risk + sleep + smoking index, $68.1 \%$ of the sample reported no risk behaviours, $22.7 \%$ reported one risk behaviour, $4.8 \%$ reported two risk behaviours, 3.2\% reported three risk behaviours, $1.1 \%$ reported four risk behaviours, and $0.1 \%$ reported all five risk behaviours.

A threshold of one or more risk behaviours on the basic risk index + sleep + smoking index was the best 


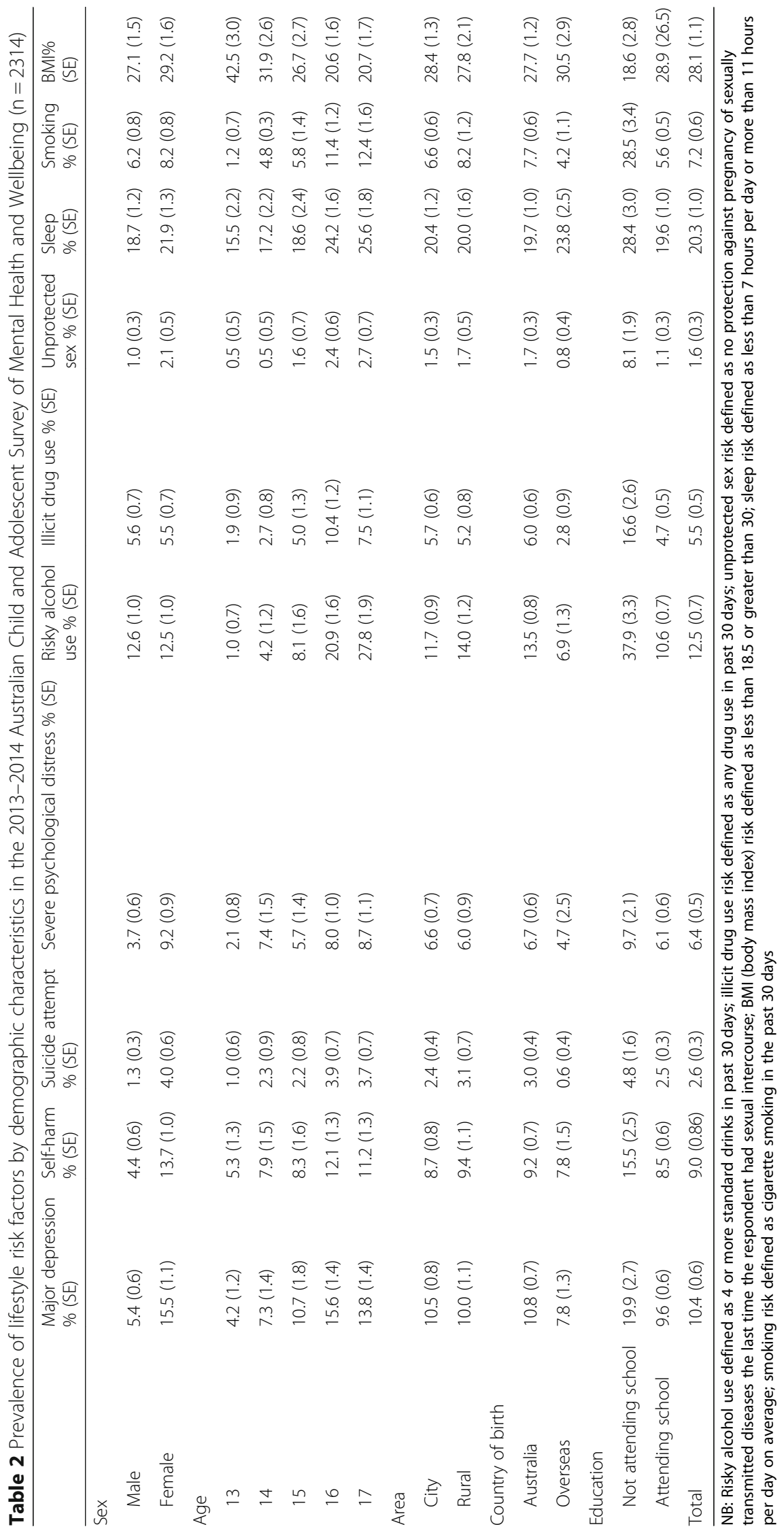


Table 3 Tetrachoric correlations between lifestyle risk factors included in the 2013-2014 Australian Child and Adolescent Survey of Mental Health and Wellbeing $(n=2314)$

\begin{tabular}{|c|c|c|c|c|c|c|}
\hline & Risky Alcohol Use & Illicit Drug Use & Unprotected Sex & $\mathrm{BMI}$ & Sleep & Smoking \\
\hline Alcohol use & 1.00 & $0.69^{b}$ & $0.25^{\mathrm{a}}$ & $-0.14^{a}$ & $0.13^{\mathrm{a}}$ & $0.65^{\mathrm{b}}$ \\
\hline Illicit drug use & & 1.00 & $0.47^{\mathrm{b}}$ & 0.01 & $0.27^{b}$ & $0.77^{b}$ \\
\hline Unprotected sex & & & 1.00 & 0.01 & 0.08 & $0.51^{b}$ \\
\hline BMI & & & & 1.00 & -0.04 & 0.05 \\
\hline Sleep & & & & & 1.00 & $0.30^{b}$ \\
\hline Smoking & & & & & & 1.00 \\
\hline
\end{tabular}

${ }^{a} p<0.01 ;{ }^{b} p<0.0001$

NB: Risky alcohol use defined as 4 or more standard drinks in past 30 days; illicit drug use risk defined as any drug use in past 30 days; unprotected sex risk defined as no protection against pregnancy of sexually transmitted diseases the last time the respondent had sexual intercourse; BMI (body mass index) risk defined as less than 18.5 or greater than 30; sleep risk defined as less than 7 hours per day or more than 11 hours per day on average; smoking risk defined as cigarette smoking in the past 30 days

predictor of depression [AUC $=0.747$ (95\% CI: 0.715, 0.779 ); sensitivity $=0.667$ (95\% CI: 0.605-0.730); specificity $=0.718(95 \% \mathrm{CI}: 0.696-0.741)]$, self-harm [AUC = 0.731 (95\% CI: 0.700, 0.762); sensitivity $=0.637$ (95\% CI: $0.569-0.705)$; specificity $=0.710(95 \% \mathrm{CI}: 0.688-0.732)$ ] and severe psychological distress $[\mathrm{AUC}=0.753$ (95\% CI: $0.714,0.793)$; sensitivity $=0.705$ (95\% CI: 0.626-0.784); specificity $=0.705$ (95\% CI: 0.683-0.727)]. A threshold of two risk behaviours was a marginally better predictor for suicide attempt [one behaviour $\mathrm{AUC}=0.797$ (95\% CI: $0.761,0.832$ ); sensitivity $=0.827$ (95\% CI: 0.726-0.928); specificity $=0.692(95 \% \mathrm{CI}: 0.670-0.715)$; two behaviour AUC $=0.806$ (95\% CI: $0.754,0.858)$; sensitivity $=0.626$ (95\% CI: $0.497-0.756)$; $\quad$ specificity $=0.919 \quad(95 \%$ CI: 0.907-0.931)], but this difference was not statistically significant $(p=0.689)$. A threshold of one or more risk behaviours on the basic risk index + sleep + smoking was therefore selected as the optimal cut-off in terms of predicting each the four causes of disease burden in adolescence. Overall, $31.9 \%$ of the sample scored above this threshold.

Table 5 displays the demographic characteristics of adolescents who were classified as 'at risk' according to the one or more threshold on the basic risk + sleep + smoking index. The odds of being classified as 'at risk' increased with age, and were greater amongst those not attending school.

\section{Discussion}

In a large, nationally representative sample of Australian adolescents, this study investigated the clustering of lifestyle risk factors, and the extent to which these clusters predicted the key causes of excessive adolescent burden of disease. A lifestyle risk index comprised of risky alcohol use, drug use, unprotected sex, sleep duration and smoking predicted each of the disease burden outcomes with the best precision. When an empirically-derived threshold of one or more risk behaviours was imposed on this index, the prediction of these health outcomes ranged from fair to good. Such a high level of predictive precision was surprising, especially given the complexity of the disease burden outcomes investigated. These results suggest that this lifestyle risk index represents a useful summary metric in the context of health promotion and non-communicable disease prevention. Major depression is predicted to become the largest contributor to burden of disease by 2030 [32], and is associated with other non-communicable diseases that contribute excessively to the burden of disease in adults, such as heart disease, cancer and Type II diabetes [33]. Prevention programs targeting these novel and potentially modifiable lifestyle risk factors in adolescence may therefore be instrumental in reducing the considerable burden of disease associated with poor mental health across the lifespan. The current study proposes a lifestyle risk factor index that could be used in these prevention programs to identify those adolescents at risk for poor mental health outcomes and who my benefit from a healthy lifestyles intervention.

Of note, this study identified sleep as an important risk factor in the prediction of adolescent disease burden. This is consistent with similar studies of the adult population [7]. Recent "calls to action" have focused on the importance of sleep, particularly given its relationship with risk behaviours associated with weight gain [17]. Longitudinal studies have also found that poor sleep quality in early adolescence is associated with earlier onset of alcohol and cannabis use [16]. There is consistent evidence to therefore suggest that sleep is an important risk factor contributing to disease burden, and should be a target for future health promotion activities.

These findings have implications for the types of lifestyle factors that may be targeted by multiple health behaviour change interventions focusing on adolescents. Some of the lifestyle factors that form the risk index were adolescent-specific contributors to burden of disease (i.e., unprotected sex and drug use) [2, 3]. Risky alcohol use and sleep duration, however, have also been 


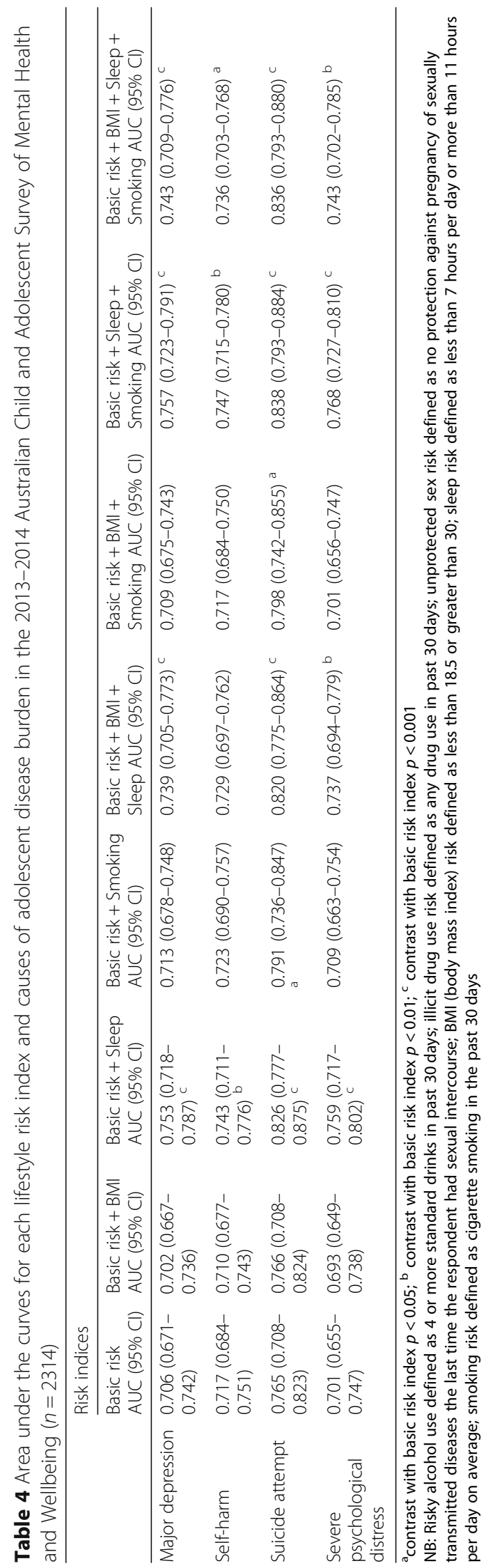


Table 5 Demographic characteristics of at risk group (i.e., those reporting one or more behaviours on the basic risk + sleep + smoking index) in the 2013-2014 Australian Child and Adolescent Survey of Mental Health and Wellbeing $(n=2314)$

\begin{tabular}{|c|c|c|c|}
\hline & $\%(\mathrm{SE})$ & Unadjusted OR (95\% Cl) & Adjusted OR (95\% Cl) \\
\hline \multicolumn{4}{|l|}{ Sex } \\
\hline Male & $30.4(1.5)$ & $1.17(0.98-1.40)$ & $0.87(0.72-1.06)$ \\
\hline Female & $33.9(1.5)$ & [ref] & [ref] \\
\hline \multicolumn{4}{|l|}{ Age } \\
\hline 13 & $16.7(2.4)$ & [ref] & [ref] \\
\hline 14 & $22.4(2.4)$ & $1.43(0.93-2.21)$ & $1.42(0.92-2.19)$ \\
\hline 15 & $26.5(2.6)$ & $1.79(1.126-2.78)^{b}$ & $1.75(1.13-2.71)^{\mathrm{a}}$ \\
\hline 16 & $43.1(1.9)$ & $3.78(2.62-5.45)^{c}$ & $3.55(2.46-5.14)^{c}$ \\
\hline 17 & $51.0(2.1)$ & $65.20(3.60-7.50)^{c}$ & $4.05(2.77-5.92)^{c}$ \\
\hline \multicolumn{4}{|l|}{ Area } \\
\hline City & $31.2(1.4)$ & [ref] & [ref] \\
\hline Rural & $33.6(1.9)$ & $1.12(0.91-1.37)$ & $1.14(0.92-1.42)$ \\
\hline \multicolumn{4}{|l|}{ Country of birth } \\
\hline Australia & $32.3(1.2)$ & $1.06(0.81-1.39)$ & $1.05(0.79-1.40)$ \\
\hline Overseas & $31.0(2.7)$ & [ref] & [ref] \\
\hline \multicolumn{4}{|l|}{ Education } \\
\hline Not attending school & $66.5(3.3)$ & $4.74(3.51-6.41)^{c}$ & $2.67(1.98-3.62)^{c}$ \\
\hline Attending school & $29.5(1.1)$ & [ref] & [ref] \\
\hline Total & $31.9 \%(1.1)$ & - & - \\
\hline
\end{tabular}

${ }^{\mathrm{a}} p<0.05 ;^{\mathrm{b}} p<0.01{ }^{\mathrm{c}} \mathrm{p}<0.001$

NB: Risky alcohol use defined as 4 or more standard drinks in past 30 days; illicit drug use risk defined as any drug use in past 30 days; unprotected sex risk defined as no protection against pregnancy of sexually transmitted diseases the last time the respondent had sexual intercourse; BMI (body mass index) risk defined as less than 18.5 or greater than 30; sleep risk defined as less than 7 hours per day or more than 11 hours per day on average; smoking risk defined as cigarette smoking in the past 30 days

identified as important predictors of adult health outcomes $[7,8]$. These findings suggest that focusing on these latter risk factors may be useful for addressing concurrent adolescent health as well as future morbidity and mortality associated with chronic diseases of adulthood. Thus, these lifestyle risk factors may therefore be particularly important to target in adolescent preventive interventions given their potential for both short- and long-term impact.

Consistent with previous research $[4,13,14,34-40]$, this study indicated that lifestyle risk factors tend to cluster together in adolescence. This clustering may occur through direct causation (i.e., unprotected sex as a result of alcohol or drug use) or shared aetiologies (i.e., social disadvantage). Given that these lifestyle risk factors are highly clustered, modifying one factor may also lead to changes in another. Historically, interventions aimed at preventing lifestyle risk factors have targeted a single factor [41]. However, the clustering of lifestyle risk factors suggests that multiple risk factors should be targeted together, rather than in isolation. Interventions designed specifically to target multiple risk factors are less resource intensive and more cost-effective than single factor interventions [41]. There is a growing literature on multiple health behaviour change interventions among adolescents and adults, but many of these are limited to small number of risk factors, and few include emerging risk factors, such as sleep duration which was identified as important in the current study [38, 41-45]. Future research should focus on developing and evaluating multiple health behaviour change interventions for adolescents and young adults, perhaps including the risk factors identified by the current study.

The current study also provides evidence as to the setting and timing of multiple health behaviour change interventions for adolescents. Youth outside of school settings are much more likely to be at risk in terms of the lifestyle factors included in this study. Whilst previous research indicates that school may be the best place for implementing "universal" prevention strategies [46], "selected" or "indicated" risk factor prevention could be considered as a means of targeting adolescents who are no longer attending school. Delivering interventions to high risk adolescents outside of school settings is a current challenge that should be prioritised. In the current study, the prevalence of these lifestyle risk factors increased with age, with a particularly sharp increase between the ages of 15 and 16 years. Although 
chronic disease prevention is advocated across the lifespan, the present findings suggest than an optimal time to deliver preventive interventions is in early adolescence, before the age 15, when these lifestyle risk factors are more likely to be initiated and before they become entrenched.

The findings from this study need to be considered within the context of its strengths and limitations. This study included data from a large, nationally representative sample of adolescents from the general population. In addition, health outcomes related to the leading global burdens of disease in adolescents were measured. Depression was assessed using a self-administered structured diagnostic questionnaire, and other health outcomes were assessed using standardised measures. Limitations of this study include its cross-sectional design. Longitudinal studies are needed to explore how these lifestyle risk factors co-vary over time to predict morbidity and mortality in adolescence through to adulthood. Risk factors and health outcomes were all self-reported, with the possibility of over- or under-reporting by participants especially with the querying of sensitive topics. Future research should also attempt to use objective measures to validate self-report of physical activity, sedentary behaviour and sleep patterns and sleep duration. There is an absence of energy balance risk behaviours in our risk index, and we included BMI as a proxy for these behaviours. Physical inactivity, diet and sedentary behaviour have been found to co-occur in adolescents [47] and to predict poor outcomes in adolescence [17] and the incidence of later cardiovascular disease, cancers and diabetes [48]. These measures were not available in the present dataset, however future research should examine these risk factors alongside those investigated in the present study as a means of further guiding intervention efforts. Finally, whilst for some lifestyle factors, risk was defined with reference to national guidelines (i.e., alcohol use, sleep and BMI) for others there were no guidelines available to determine risk thresholds (i.e., drug use, unprotected sex and smoking). However, due to their illegality and/or the dire consequences associated with these behaviours, it could be argued that any involvement in these behaviours constitutes significant risk.

\section{Conclusions}

In a large, nationally representative sample of Australian adolescents, a lifestyle risk index comprised of risky alcohol use, drug use, unprotected sex, sleep duration and smoking was a fair to good predictor of health outcomes associated with the leading fatal (suicide attempt and self-harm) and non-fatal (major depression and severe psychological distress) global burdens of disease amongst adolescents. This study indicates that this lifestyle risk index represents a useful summary metric in the context of adolescent health promotion and non-communicable disease prevention. Lifestyle risk factors were found to cluster in adolescence, providing further support for the implementation of multiple health behaviour change interventions over those with a single behaviour focus. Future research should focus on determining whether this lifestyle risk index predicts adolescent health outcomes in a longitudinal framework.

\section{Abbreviations \\ AUC: Area Under the Curve; BMI: Body Mass Index; DISC-IV: Diagnostic Interview Schedule for Children 4th Edition; K10: Kessler Psychological Distress Scale; MDD: Major Depressive Disorder; YRBSS: Youth Risk Behavior Surveillance System \\ Acknowledgements \\ Not applicable. \\ Funding \\ Dr. Mewton is funded by an Australian Rotary Health Postdoctoral Fellowship. Australian Rotary Health had no role in the design of the study and collection, analysis, and interpretation of data and in writing the manuscript.}

\section{Availability of data and materials}

The datasets analysed during the current study are available from the Telethon Kids Institute. Data are released under special restricted access, which requires users to have obtained ethics approval for their research. Details can be accessed here: https://youngmindsmatter.telethonkids.org.au/ siteassets/media-docs\%2D\%2D-young-minds-matter/data-accessstatement2.pdf

\section{Author contributions}

LM, KC, MS, FK-L, LT and MT contributed to the concept and design of the study. LM analysed and interpreted the data and wrote the first draft of the manuscript. LM, KC, MS, FK-L, LT and MT contributed to subsequent drafts and read and approved the final manuscript.

\section{Ethics approval and consent to participate}

This study was approved by the University of New South Wales Human Research Ethics Committee. Adolescents and their parents provided informed written consent to participate in the Australian Child and Adolescent Survey of Mental Health and Wellbeing.

\section{Consent to publish}

Not applicable.

\section{Competing interests}

The authors declare that they have no competing interests.

\section{Publisher's Note}

Springer Nature remains neutral with regard to jurisdictional claims in published maps and institutional affiliations.

Received: 8 May 2018 Accepted: 4 January 2019

Published online: 14 January 2019

References

1. Blum RW. Young people: not as healthy as they seem. Lancet. 2009; 374(9693):853-4.

2. Patton GC, Coffey C, Sawyer SM, Viner RM, Haller DM, Bose K, Vos T, Ferguson J, Mathers CD. Global patterns of mortality in young people: a systematic analysis of population health data. Lancet. 2009;374(9693): 881-92.

3. Australian Institute of Health and Welfare: Australian Burden of Disease Study: Impact and causes of illness and death in Australia 2011. In Canberra; 2016. 
4. Pronk NP, Anderson LH, Crain AL, Martinson BC, O'Connor PJ, Sherwood NE, Whitebird RR. Meeting recommendations for multiple healthy lifestyle factors: prevalence, clustering, and predictors among adolescent, adult, and senior health plan members. Am J Prev Med. 2004;27(2):25-33.

5. Poortinga $W$. The prevalence and clustering of four major lifestyle risk factors in an English adult population. Prev Med. 2007;44(2):124-8.

6. Fine LJ, Philogene GS, Gramling R, Coups EJ, Sinha S. Prevalence of multiple chronic disease risk factors: 2001 National Health Interview Survey. Am J Prev Med. 2004;27(2):18-24.

7. Ding D, Rogers K, Macniven R, Kamalesh V, Kritharides L, Chalmers J, Bauman A. Revisiting lifestyle risk index assessment in a large Australian sample: should sedentary behavior and sleep be included as additional risk factors? Prev Med. 2014;60:102-6

8. Loef $M$, Walach $H$. The combined effects of healthy lifestyle behaviors on all cause mortality: a systematic review and meta-analysis. Prev Med. 2012; 55(3):163-70.

9. $\quad$ Spring B, Moller AC, Coons MJ. Multiple health behaviours: overview and implications. J Public Health. 2012;34(suppl_1):i3-i10.

10. McCullough ML, Patel AV, Kushi LH, Patel R, Willett WC, Doyle C, Thun MJ, Gapstur S: Following cancer prevention guidelines reduces risk of cancer, cardiovascular disease and all-cause mortality. Cancer Epidemiol Biomarkers Prev 2011:cebp 1173.2010.

11. Masi S, Charakida M, Wang G, O'Neill F, Taddei S, Deanfield J. Hope for the future: early recognition of increased cardiovascular risk in children and how to deal with it. Eur J Cardiovasc Prev Rehabil. 2010, 16:S61.

12. Bannink R, Broeren S, Heydelberg J, van't Klooster E, Raat H. Depressive symptoms and clustering of risk behaviours among adolescents and young adults attending vocational education: a cross-sectional study. BMC Public Health. 2015;15(1):396.

13. Flisher AJ, Kramer RA, Hoven CW, King RA, Bird HR, Davies M, Gould MS, Greenwald S, Lahey BB, Regier DA. Risk behavior in a community sample of children and adolescents. J Am Acad Child Adolesc Psychiatry. 2000;39(7):881-7.

14. Carli V, Hoven CW, Wasserman C, Chiesa F, Guffanti G, Sarchiapone M, Apter A, Balazs J, Brunner R, Corcoran P. A newly identified group of adolescents at "invisible" risk for psychopathology and suicidal behavior: findings from the SEYLE study. World Psychiatry. 2014;13(1):78-86.

15. Meng L, Maskarinec G, Lee J, Kolonel LN. Lifestyle factors and chronic diseases: application of a composite risk index. Prev Med. 1999:29(4):296-304.

16. Mike TB, Shaw DS, Forbes EE, Sitnick SL, Hasler BP. The hazards of bad sleep-sleep duration and quality as predictors of adolescent alcohol and cannabis use. Drug Alcohol Depend. 2016;168:335-9.

17. Chaput J-P, Dutil C. Lack of sleep as a contributor to obesity in adolescents: impacts on eating and activity behaviors. Int J Behav Nutr Phys Act. 2016; 13(1):103.

18. Hafekost J, Lawrence D, Boterhoven de Haan K, Johnson SE, Saw S, Buckingham WJ, Sawyer MG, Ainley J, Zubrick SR. Methodology of young minds matter: the second Australian child and adolescent survey of mental health and wellbeing. Aus N Z J Psychiatry. 2016;50(9):866-75.

19. Shaffer D, Fisher P, Lucas CP, Dulcan MK, Schwab-Stone ME. NIMH diagnostic interview schedule for children version IV (NIMH DISC-IV): description, differences from previous versions, and reliability of some common diagnoses. J Am Acad Child Adolesc Psychiatry. 2000;39(1):28-38.

20. Brener ND, Kann L, Kinchen SA, Grunbaum JA, Whalen L, Eaton D, Hawkins J, Ross JG. Methodology of the youth risk behavior surveillance system. MMWR Recomm Rep. 2004;53(RR-12):1-13.

21. Kessler RC, Barker PR, Colpe LJ, Epstein JF, Gfroerer JC, Hiripi E, Howes MJ, Normand S-LT, Manderscheid RW, Walters EE. Screening for serious mental illness in the general population. Arch Gen Psychiatry. 2003; 60(2):184-9.

22. Mewton L, Kessler RC, Slade T, Hobbs MJ, Brownhill L, Birrell L, Tonks Z, Teesson M, Newton N, Chapman C. The psychometric properties of the Kessler psychological distress scale (k6) in a general population sample of adolescents. Psychol Assess. 2016;28(10):1232-42.

23. Andrews $G$, Slade T. Interpreting scores on the Kessler psychological distress scale (K10). Aust N Z J Public Health. 2001;25(6):494-7.

24. Chan SM, Fung TCT. Reliability and validity of K10 and K6 in screening depressive symptoms in Hong Kong adolescents. Vulnerable Children and Youth Studies. 2014;9(1):75-85.

25. Green JG, Gruber MJ, Sampson NA, Zaslavsky AM, Kessler RC. Improving the K6 short scale to predict serious emotional disturbance in adolescents in the USA. Int J Methods Psychiatr Res. 2010;19(0 1):23.
26. National Health and Medical Research Council: Australian guidelines to reduce health risks from drinking Alcohol In. Canberra: Commonwealth of Australia; 2009.

27. About Overwieght and Obesity [http://www.health.gov.au/internet/main/ publishing.nsf/content/health-pubhlth-strateg-hlthwt-obesity.htm ].

28. De Wit LM, Van Straten A, Van Herten M, Penninx BW, Cuijpers P. Depression and body mass index, a u-shaped association. BMC Public Health. 2009;9(1):14.

29. Association AP: Diagnostic and statistical manual of mental disorders (DSM$\left.5^{\oplus}\right)$ : American psychiatric pub; 2013

30. Hirshkowitz M, Whiton K, Albert SM, Alessi C, Bruni O, DonCarlos L, Hazen N, Herman J, Katz ES, Kheirandish-Gozal L. National Sleep Foundation's sleep time duration recommendations: methodology and results summary. Sleep Health. 2015;1(1):40-3

31. DeLong ER, DeLong DM, Clarke-Pearson DL. Comparing the areas under two or more correlated receiver operating characteristic curves: a nonparametric approach. Biometrics. 1988:837-45.

32. Mathers CD, Loncar D. Projections of global mortality and burden of disease from 2002 to 2030. PLoS Med. 2006;3(11):e442

33. Moussavi S, Chatterij S, Verdes E, Tandon A, Patel V, Ustun B. Depression, chronic diseases, and decrements in health: results from the world health surveys. Lancet. 2007:370(9590):851-8.

34. Mays D, Peshkin BN, Walker LR, Abraham AA, Hawkins KB, Tercyak KP. Patterns and correlates of multiple risk factors for adult-onset cancer among adolescents1. J Child Health Care. 2012;16(3):250-62.

35. van Nieuwenhuijzen $M_{1}$ Junger $M$, Velderman $M K$, Wiefferink $K H$, Paulussen TW, Hox J, Reijneveld SA. Clustering of health-compromising behavior and delinquency in adolescents and adults in the Dutch population. Prev Med. 2009:48(6):572-8.

36. Plotnikoff RC, Karunamuni N, Spence JC, Storey K, Forbes L, Raine K, Wild TC, McCargar L. Chronic disease-related lifestyle risk factors in a sample of Canadian adolescents. J Adolesc Health. 2009;44(6):606-9.

37. Sanchez A, Norman GJ, Sallis JF, Calfas KJ, Cella J, Patrick K. Patterns and correlates of physical activity and nutrition behaviors in adolescents. Am J Prev Med. 2007:32(2):124-30.

38. Prochaska JJ, Spring B, Nigg CR. Multiple health behavior change research: an introduction and overview. Prev Med. 2008:46(3):181-8.

39. Coleman C, Wileyto EP, Lenhart CM, Patterson F. Multiple health risk behaviors in adolescents: an examination of youth risk behavior survey data. Am J Health Educ. 2014:45(5):271-7.

40. Dodd LJ, Al-Nakeeb Y, Nevill A, Forshaw MJ. Lifestyle risk factors of students: a cluster analytical approach. Prev Med. 2010;51(1):73-7.

41. King K, Meader N, Wright K, Graham H, Power C, Petticrew M, White M, Sowden AJ. Characteristics of interventions targeting multiple lifestyle risk behaviours in adult populations: a systematic scoping review. PLoS One. 2015;10(1):e0117015.

42. Nigg CR, Long CR. A systematic review of single health behavior change interventions vs. multiple health behavior change interventions among older adults. Transl Behav Med. 2012;2(2):163-79.

43. James E, Freund M, Booth A, Duncan MJ, Johnson N, Short CE, Wolfenden L, Stacey FG, Kay-Lambkin F, Vandelanotte C. Comparative efficacy of simultaneous versus sequential multiple health behavior change interventions among adults: a systematic review of randomised trials. Prev Med. 2016;89:211-23.

44. Oosterveen E, Tzelepis F, Ashton L, Hutchesson MJ. A systematic review of eHealth behavioral interventions targeting smoking, nutrition, alcohol, physical activity and/or obesity for young adults. Prev Med. 2017.

45. Busch V, de Leeuw JRJ, de Harder A, Schrijvers AJP. Changing multiple adolescent health behaviors through school-based interventions: a review of the literature. J Sch Health. 2013;83(7):514-23.

46. Wiefferink $\mathrm{CH}$, Peters L, Hoekstra F, Ten Dam G, Buijs GJ, Paulussen TG. Clustering of health-related behaviors and their determinants: possible consequences for school health interventions. Prev Sci. 2006;7(2):127.

47. Pearson N, Griffiths P, Biddle SJ, Johnston JP, McGeorge S, Haycraft E. Clustering and correlates of screen-time and eating behaviours among young adolescents. BMC Public Health. 2017;17(1):533.

48. Ezzati M, Riboli E. Behavioral and dietary risk factors for noncommunicable diseases. N Engl J Med. 2013;369(10):954-64. 